\title{
Valuation of Mineral Resources in Selected Financial and Accounting Systems
}

\author{
Robert Uberman \\ A.F. Modrzewski Kraków Academy, Kraków, Poland \\ Email: robertuberman@poczta.onet.pl
}

Received 25 May 2014; revised 21 June 2014; accepted 5 July 2014

Copyright (C 2014 by author and Scientific Research Publishing Inc.

This work is licensed under the Creative Commons Attribution International License (CC BY). http://creativecommons.org/licenses/by/4.0/

(c) (i) Open Access

\begin{abstract}
The paper presents reviews of fundamental issues regarding valuation methodologies of mineral deposits: 1) recommended by mineral industry standards; 2) used for disclosures in financial statements and 3) adopted in national statistics. A discussion of historical developments of various regulations is supplemented by characteristics of key valuation methods. Differences and similarities are analysed and compared to current practices. A special attention is given to certain distinctive issues which are not shared by most of other types of assets like inclusion of decommissioning and rehabilitation costs or consequences of long duration of investment phase.
\end{abstract}

\section{Keywords}

Mineral Resources, Valuation, Accounting for Mineral Assets, Valuation Codes

\section{Introduction}

One of the most striking paradoxes about value of mineral resources comes from a fact that although almost everybody consents that mineral deposits are, at least in some cases, extremely valuable, there is little agreement about how this value should be disclosed. This assertion refers to mining companies' reports, especially financial statements, but also to national accounts as well as to valuations made on ad hoc bases for various and growing number of purposes and customers. Relatively slow progress in development of regulations related to recognition and valuation of mineral deposits as a class of assets results from a low number of countries where mining has become an important part of their economy and even a smaller number amongst them have developed mature financial markets creating a need for a large number of valuations. In several countries, professional organizations of appraisers have been founded-Australia, Canada and South Africa may serve as prominent examples. Nearly all of them have undertaken efforts to codify rules and methodologies of mineral deposits valuation. Simultaneously, mineral resources has drawn attention of accountants both corporate and na- 
tional. The former group has been facing a problem of different treatments of mineral resources in various national accounting standards leading to slow development of universally recognized rules under International Accounting Standards (IAS). The latter one struggles to include mineral resources into national accounts.

"Mineral assets" is a broad notion, covering not only mineral deposits but also various rights regarding their exploration, development and mining. It is strongly related to decommissioning and rehabilitation issue since exploitation usually affects natural environment, sometimes very aggressively. Therefore it is unreasonable to expect that a few universally recognised standards regarding their valuation will be developed soon, if ever. Instead one may expect a gradual harmonization of a handful of regulations covering the most important issues.

\section{Valuation Rules for Mineral Resources Set by National Valuation Codes and International Valuation Standards}

A growing number of transactions and of mining companies with shares quoted on regulated markets created a need for transparent regulations, at least in some countries. The intent was to give investors and other stakeholders a certain level of comfort regarding quality and usefulness of valuations of mineral deposits. The first widely recognized standard was provided by the Australian VALMIN Code. It was developed by a joint committee of The Australasian Institute of Mining and Metallurgy, Australian Institute of Geoscientists (AIG) and Mineral Industry Consultants Association Inc. (MICA—now the Consultants Society of The AusIMM), in consultation with the Australian Securities and Investment Commission, the Australian Stock Exchange Limited, the Minerals Council of Australia, the Petroleum Exploration Society of Australia, the Securities Association of Australia and representatives from the Australian financial sector.

The VALMIN Code was first adopted on 17 February 1995 and applied to all relevant Reports required under the Corporations Law from 1 July 1995. It was amended on 22 November 1997 and applied to all relevant Reports required under the Corporations Law issued on or after 1 April 1998. The VALMIN Code 2005 was approved on Friday 29 April 2005 and superseded all earlier versions of the code.

AusIMM effort was followed by the Canadian Institute of Mining, Metallurgy and Petroleum (CIM). In January 1999 the Mining Standards Task Force of the Toronto Stock Exchange and the Ontario Securities Commission recommended that the CIM establishes a committee to review and advice on approaches and methodologies for the valuation of mineral properties. Subsequently that year, CIM established a Special Committee on Valuation of Mineral Properties (CIMVal). The committee consisted of experts and practitioners from the consulting, financial, investment, mining operations and legal sectors. CIMVal was adopted by CIM Council in February 2003. The code is also required by the Toronto Stock Exchange-Venture (TSX-V) under its regulations.

Subsequent to efforts of AusIMM and CIM, organizations of mining experts in several other countries attempted to develop their own codes. One may give examples of South Africa (SAMVAL), USA (USMinval) and Poland (POLVAL).

Achievements of national valuation codes got recognised by inclusion of International Valuation Guidance Note No 14 named "Valuation of Properties in the Extractive Industries" into Seventh Edition of International Valuation Standards in 2005.

The above indicated codes share some important features regarding scope of mineral assets considered, preferred valuation methodologies (as well as aspects not discussed in this article like: required qualifications of experts conducting the valuation process as well as ethical norms and guidelines).

First of all they define mineral assets (or property). Usually definitions consider two important groups as belonging to the assets in consideration:

1) Rights, titles or interests to property held or acquired in connection with the exploration, development, extraction or processing of minerals regardless whether located on or under the surface of such property;

2) All equipment and infrastructure owned or acquired for the exploration, development, extraction and processing of minerals in connection with such properties including mines and processing plants [1] [2].

Due to various legal systems and historical developments a list of legal and similar rights included into the definitions of mineral assets is particularly long. It comprises of unpatented mining claims, prospecting permits, prospecting licenses, reconnaissance permits, reconnaissance licenses, exploration permits, exploration licenses, development permits, development licenses, mining licenses, mining leases, royalty interests to list the most commonly indicated [1].

International Valuation Standards use a term "Properties in Extractive Industries” and remain surprisingly 
vague in defining them. Although they leave no doubt that mineral resources in situ as well as all legal titles and claims pertaining to them are covered by the above indicated Guidance Note, one cannot find any clear-cut statement on equipment and infrastructure. However p. 5.1.3 states that process of mining contributes actively to the Going Concern Value of the enterprise.

As regards the scope of assets considered in the above analysed documents the most fundamental issue refers to an inclusion or exclusion of hydrocarbons (primary oil and gas). Petroleum industry in any terms overshadows all other extractive activities and stands on a forefront of developments in various areas of finance, both as science and as a practice. Although there is little doubt that hydrocarbons meet general definition of mineral resources and in various countries are recognized as such, most of researches and practitioners tend to treat them separately from other minerals. However even on a level of basic geological classifications there is a considerable amount of confusion. In certain systems all fossil fuels and uranium are treated as a separate group or groups. In some only conventional oil and gas is distinguished while coal as well as a limited number of unconventional crudes is included into mineral resource. United Nations Framework Classification (UNFC) adopted a notion "for Energy and Mineral Resources" thus eliminating a need, at least on general level, to decide on hydrocarbons status, which naturally belong to energy resources [3]. Although designed as a classification in its own right it is constructed to make it "very suitable for comparing with other classifications through mapping modules, and thus it can be used to facilitate their harmonization through highlighting changes that could be implemented to remove material differences between them". Consequently a procedure of either subdividing or aggregating categories may be applied at the national or numerous other levels to meet specific needs arising for instance from national legislation, corporate decision procedures and various others. Thus one of the aims of UNFC preparation was to allow a common understanding of these specific classifications/evaluations.

A mineral resources reporting system most commonly observed by resource companies is the JORC Code. Created in Australia and widely recognized in many other countries which clearly restricts itself only to solid minerals [4], thus leaving oil \& gas outside it’s scope. Even in Australia a separate Petroleum Resources Management System was created just for hydrocarbons. But globally the one most commonly followed was: Guidelines for Application of the Petroleum Resources Management System created by Society of Petroleum Engineers (expanded version of well-known Guidelines for Evaluation of Reserves and Resources).

Another area on which national valuation codes tend to be very specific is classification of mineral assets into categories defined by a phase of exploration life-time. CIMVAL [1] identifies four types:

1) Exploration Properties,

2) Mineral Resource Properties,

3) Development Properties,

4) Production Properties.

VALMIN distinguishes: Exploration Areas, Advanced Exploration Areas, Pre-Development Projects, Development Projects and Operating Mines. Both Codes recognize also Mines in Closure as somehow specific type of mineral assets. The Polish POLVAL is the most complete in these terms and offers the following categorisation of mineral assets' development stages:

1) Exploration,

2) Identification and documenting,

3) Design and development,

4) Exploitation,

5) Closure, decommissioning and rehabilitation.

It is important to note that definitions of mineral assets adopted by national valuation codes are quite broad and expand well beyond the boundaries set by common understanding of the notion "mineral deposits". Moreover they cover assets belonging to various classes if classifications used by accounting or legal regulations are applied. It might come as a surprise that in practice mineral assets may be more often intangible than tangible, on the contrary to common logic suggesting that something so solid as rock has to be tangible. Mentioned above rights, titles or interests connected with the exploration and development usually are separated from the ownership of land while surface of such property may be used for other purposes. On the other side mineral assets definition often includes items otherwise classified as PPE (Property, Plant and Equipment) such as all plant, equipment and infrastructure owned or acquired for the development, extraction and processing of minerals [2]. In practice this broadness of definition does not post a challenge for an experienced valuator applying income or cost based approach. In most cases it is quite clear which assets are necessary for exploration or extracting ac- 
tivities. In addition a nature of mining usually prevents from any shared use of importance to the process. The real problem starts with a proper application of the market based one. Complexity of mineral assets combined with their limited applicability for other purposes leads to necessity of expanded adjustments very often based on very subjective judgments.

As far as methodologies considered and recommended national valuation codes follow, directly or indirectly all recognized approaches in the area:

1) Income approach;

2) Cost approach;

3) Sales comparison approach.

The only exception is VALMIN which refrains from giving any specific guidelines regarding this matter.

\section{Disclosures on Mineral Resources Required under Current Accounting Regulations}

\subsection{Commonly Required Disclosures}

The widely recognized definition of mineral resources can be presented as follows: "a concentration of naturally occurring solid, liquid, or gaseous material, in or on the earth's crust, in such form and amount that economic extraction of a commodity from the concentration is currently or potentially feasible" [5] where feasible shall be interpreted as economically beneficial or profitable. Resources that are both currently profitable to exploit and known with considerable certainty are called reserves. Therefore their value is a function of price paid for extracted material and extraction costs. Since mining process expands over long time in future a time value of money concept has to be applied.

Very often a discussion what kind of benefits belong to a given mineral asset owner is omitted or extremely simplified. Definitely this is not only an academic problem. Since valuing mineral assets means in practice valuing owner's benefits on cannot avoid defining them properly. This issue is quite complicated in case of mineral resources since they often are amalgamated irrevocably with other properties like land, mining infrastructure and machines.

\subsection{Proved Reserve Quantities}

Proved reserves quantities are reported according to proprietary classification systems developed by Oil and Gas companies themselves but modelled after a scheme developed and approved by the Society of Petroleum Engineers, the World Petroleum Congress and the American Association of Petroleum Geologists. The system classifies recoverable hydrocarbons into six categories based on their status at the time of reporting - three deemed commercial and three potentially recoverable. Within the commercial classification are proved reserves and two categories of unproved: probable and possible. The potentially recoverable categories are also referred to as contingent resources. For reserves estimates to be classified as proved they must meet all SEC standards. In practice oil companies report oil, gas and condensate separately. Oil and condensate volumes are given in barrels while gas in cubic feet. Even though they seem to be very basic data, there is a considerable amount of judgments applied in their preparation. At least once, in case of Royal Dutch Shell, proved reserves quantities reported were successfully challenged and this renowned corporation was forced to admit overstatement of proved reserves reported by $10 \%$ in 2003 but by as much as $26 \%$ in 1999 .

In all other cases reporting of mineral reserves and/or resources is based on general accounting rules prescribing disclosure of all material information influencing a financial position of the reporting company. Where mining activities contribute vastly to profitability of a given company such disclosures may be considered mandatory under various regimes [6].

\subsection{Capitalized Exploration and Development Costs}

Capitalized exploration and development costs reflect historical cost approach to asset valuation, still the accepted by accounting standards and commonly used. One counts among them those incurred in connection with acquisition of rights to explore, investigate, examine and evaluate an area for mineralization. Exploration may be conducted before or after the acquisition of mineral rights [7] [8]. IFRS 6 mentions the following examples of expenditures (the list is not exhaustive): 
- Acquisition of rights to explore;

- Topographical, geological, geochemical and geophysical studies;

- Exploratory drilling;

- Trenching;

- Sampling;

- Activities in relation to evaluating the technical feasibility and commercial viability of extracting a mineral resource [9].

An important restriction has been added forbidding application of IFRS 6 to expenditures incurred:

- Before the exploration for and evaluation of mineral resources, such as expenditures incurred before the entity has obtained the legal rights to explore a specific area.

- After the technical feasibility and commercial viability of extracting a mineral resource are demonstrable [9]. According to the relevant KPMG study [7] development costs typically include those incurred for the design of the mine plan, obtaining the necessary permits, constructing and commissioning the facilities and preparation of the mine and necessary infrastructure for production. The mine development phase generally begins after completion of a feasibility study and ends upon the commencement of commercial production.

The last provision, although makes impression of being precise, in practice leaves space for various interpretations. Some companies adopt approach in which commencement of commercial production is defined not in terms of real beginning of operations but in terms of ability to do so. Some others try to set a cut off point at the beginning of underground works.

\subsection{Challenges Posted by Accounting Valuation Rules}

There are important obstacles in identifying a universally recognized method (or methods) of mineral assets valuation applicable in financial statement. They result directly from the nature of only two fundamental valuation approaches allowed by financial accounting rules (represented here by International Financial Reporting Standards):

1) Historical cost model;

2) Revaluation model.

Both approaches are only incidentally useful for a mineral deposits valuation, regardless its purpose. Cost approach can render meaningful results only in case assets under valuation have been purchased via a market based transaction and only as long as key factor conditioning value rendered have prevailed. In fact in case of mineral deposits discovered or explored by their current owners the cost approach is near useless. The same might be stated for assets acquired in a distant past when economic conditions were substantially different from present ones.

Revaluation model, often regarded as belonging to market approach, has very specific meaning in financial accounts in reference to intangible assets (to which mineral assets are usually classified). Their value must be determined in reference to so called active market which is characterized by three following features:

1) Items traded on the market are homogeneous;

2) Willing buyers and sellers can normally be found any time;

3) Prices are available to the public.

It is easy to identify that although many commodities originated from mining activities could possibly meet the above mentioned requirements mineral deposits themselves hardly do.

\section{Valuation Method's Adopted in National Accounts}

\subsection{Valuation of Mineral Deposits as Part of Environmental Accounting: A Historical Perspective}

From the perspective of national accounts mineral assets valuation appears primary as a part of so called environmental accounting, alongside with timber, land, energy and water resources [10]. It has become a popular section within finance and accounting sciences and practice on wave of growing interest in natural resources management and change of climate. It became clear that scarcities of natural resources would threaten the sustained productivity of the economy, and economic production. Conventional national accounts, while focusing on market transactions and indicators reflecting important factors in welfare generations suffered from lack of 
appropriate methods to measure welfare available to humans but not created via human effort.

One of the very first attempts to include valuation of mineral resources into national accounts took place in the US as a reaction to the demand for regulation of the exploitation of exhaustible natural resources by the Conservation Movement, which had been particularly strong in the U.S. during the period 1890 to 1920 . It resulted with researches undertaken by Harald Hotelling who published in 1931 then very famous and influential paper on economics of exhaustible resources [11]. Most probably it was the first theory in its modern sense related solely to valuation of mineral assets, putting forward definitely one of the most influential and controversial concept regarding this issue which subsequently became known as the Hotelling Rule [12]. This publication marked also a peak in economists' attention to natural resources which was directed swiftly to other more pressing issues: Great Depression and World War II. The issue of adequacy of natural resources for sustained economic growth became a concern during the Cold War and gave birth to the President's Materials Policy Commission (Paley Commission), whose report was made public in 1952, and, as an outgrowth, to Resources for the Future, the in influential Washington think tank. Resources for the Future sponsored the publication in 1963 of Scarcity and Growth, by Harold Barnett and Chandler Morse [13], which was the first systematic analysis of long run scarcity measures of a number of natural resources. From 70s on a string of notable papers [14] has been published from which one should indicate efforts of Nordhaus [15], Pindyck [16] as well as Dasgupta and Heal [17].

The growing worldwide awareness of environmental issues lead to a conclusion that natural resources should be treated as valuable assets, thus valued in monetary terms. Amongst several others (like forests, fisheries, arable land) mineral resources had been included to almost all studies regarding natural resources assessments. The first widely recognized international result of researches came with in 1993 with edition of the Handbook of national accounting: Integrated environmental and economic accounting [18] which was created following requests made by the 1992 United Nations Conference on Environment and Development (Earth Summit) in Rio de Janeiro. It was based on numerous approaches to environmental accounting, pioneered in a series of workshops by the United Nations Environment Programme (UNEP) in collaboration with the World Bank. The handbook also pioneered the notion of System of integrated Environmental and Economic Accounts (SEEA) which then became a widely recognised expression describing part of national accounts devoted to natural resources. From the very beginning mineral assets, defined under the notion of subsoil assets, were considered within the SEEA framework. Also measuring of their value was one of the four broad categories considered, alongside with physical flows of materials, environment related transactions and measuring impact of the economy on environment [19].

SEEA was meant as a framework to compile statistics, linking environmental statistics to economic statistics. This means that the definitions, guidelines and practical approaches of the System of National Accounts (SNA) are applied to the SEEA. As a consequence the environmental statistics might be compared to economic statistics as the system boundaries are the same. Certainly on the level of data processing a need for numerous adjustments was recognized. Thus, by analysing statistics on the economy and the environment at the same time it became possible to show different patterns of sustainability for production and consumption. It could also show the economic consequences of not only of extraction of mineral resources but also of their depletion.

The handbook was subsequently supplemented by publication of an operational manual in 2000 [20] and by its new edition in 2003 [19], then with cooperation of the World Bank, IMF, OECD and European Commission. Simultaneously, a so called London Group was created in 1993 to allow practitioners to share their experience of developing and implementing environmental accounts linked to the System of National Accounts. The name is derived from the place of its first meeting in March 1994 which was held in the UK capital city. The London Group is an informal gathering of experts, primarily from national statistical agencies but also international organizations. It's meetings provide a forum for review, comparison and discussion of work underway by participants towards development of environmental accounts and become influential stage for methodological discussion on mineral assets valuation.

\subsection{Scope of Mineral Deposits Valuation within the Framework of Environmental Accounting}

Natural resources are to be included into the accounts to make it possible to describe stocks and changes in stocks in monetary terms. Therefore issue of the valuation of this natural capital, the physical quantities and 
qualitative aspects that tend not to have market monetary value, yet, becomes essential. Facing this challenge, in course of work on SEEA several key issues regarding valuation of mineral deposits had been identified and addressed:

1) Inclusion or exclusion certain items from the scope;

2) Relation between exploration expenses and value of mineral resources;

3) Relation between developed mineral resources and associated investment in fixed assets;

4) Recognition of decommissioning extractive structures as well as recovery of land.

Issue of scope has two dimensions. The first one refers to minerals recognized in national statistics. Generally countries tend to report hydrocarbons, coal, metallic crudes. But even here difference occurs. It is would be useless to discuss issues associated with conventional and non-conventional gas and oil. But in another area, a lack of congruence is similarly evident. Some countries investigate brown coal resources, some do not. Similarly in case of metal crudes covered one my find different approaches. Secondly the discussion relates to geological systematics of mineral assets. Unfortunately, as already indicated above, despite numerous efforts [21], no universally recognized system regarding classification of mineral deposits has been developed yet. Therefore countries defer substantially as to what level of exploration entitles given deposit to be included into statistics. For example Australia and New Zealand use the JORC (Joint Ore Reserves Committee) code as this is the classification system used by the minerals industry in New Zealand and Australia and it recognizes only proven and probable reserves which are the only ones valued as assets. United Kingdom use notions of discovered (proven, probable, and possible) and undiscovered resources as base for its classification where undiscovered category is given within lower and upper ranges. But the biggest differences refer to minerals used in chemical industry and construction. Here it is even difficult to establish any common framework [22].

The special cases of valuation of mineral assets value refers to the relationship between exploration costs and valuation of new discoveries "in situ". In commercial accounts these exploration costs are usually treated as a form of capital formation and recognized in form of "capitalized expenses". In recognition of the fact that the benefits of exploration efforts are usually substantially delayed from 1993 SNA introduced mineral exploration as a new category of intangible fixed capital. Expenditures in consideration shall include pre-license costs, license and acquisition costs, appraisal costs and the costs of actual test drilling and boring, as well as the costs of aerial and other surveys, transportation costs, etc., incurred to make it possible to carry out the tests [19]. Such solution posts a danger of double counting. Should a market exist in parallel for geological information and deposits themselves, the market price would be possible to get identified easily. Regretfully such situation rarely occurs. Therefore special methods had to be adopted to assure both credible appropriation of value between exploration and mineral deposits.

Mineral exploration costs issue relates to another one that often has to be solved within the framework of national accounts- the ownership issue. In many cases an ultimate title to natural resources belongs to a state regardless of specific arrangements enabling various entities to perform activities like exploration, documenting, extraction. Leaving apart the issue of mineral exploration assets presented above and assuming that a given mineral deposit has entered any further stage of development SEEA offers two options with the choice depending primary on terms of relevant agreement [19]:

1) if these allow the extractor to retain some of the resource rent of the asset, it would seem appropriate even in the SNA to record the value of the mineral deposit as divided between the owner and the extractor according to the proportions each is expected to receive;

2) if the agreement with the extractor in effect gives him ownership rights by ceasing all important decisions, especially about extraction times and volumes in return for a financial consideration than the owner will disclose a financial claim instead of the deposit while the extractor will recognise the deposit as an asset alongside with the financial liability offsetting it.

Valuation of mineral and energy resources is often additionally complicated by the means of recording associated investment in produced assets. From a purely theoretical point of view value of fixed assets employed in extracting activities shall be differentiated from the value of deposits themselves. SEEA fully supports this preposition focusing instead on practical calculation problems. Admitting extreme difficulties in using market or cost based approaches it gives in depth consideration to recognition of this issue in income based approach.

Giving aims and scope of SEEA an understandably extensive deliberation is given to the problem of decommissioning of mines and well rigs. It recognizes that in case of mining sites most of environmental protection costs are actually incurred at the end of their useful life. It points out that the major difficulty here is derived 
from the fact that as oppose to disposals of majority of other assets in the case of mining decommissioning costs are incurred at the end or after the life of the owning enterprise when there is no income against which to set these costs. They must not be neglected though. It is clearly stated that at the end of a produced asset's life, the residual value in the balance sheet should be exactly zero. Consequently residual items must no longer present any risk of damage in future and land used in extraction should have been reclaimed. The value of the terminal costs represents the cost of improving components of environment to their desired states [19].

\subsection{Methods of Mineral Deposits Valuation within the Framework of Environmental Accounting}

The preferred approach for valuing assets within the SEEA framework is the market based one. However, in the case of subsoil assets, it is swiftly admitted that in practice there may not be enough transactions to create a meaningful data base. Sales of subsoil deposits take place infrequently, sometimes through a complex arrangement (for example as a part of a merger) and consequently the information on market prices for them is very limited. For countries where the subsoil deposits are held privately there is likely to be more information on sales than in countries where all or substantial part of subsoil deposits are owned by the government [19].

In view of the above the value of mineral assets is usually determined by the present value of the expected net returns resulting from their commercial exploitation despite uncertainty and need of revision [18]. This directly leads to the concept of the resource rent which ought to represent net return on mineral assets, thus a monetary flow based on pure ownership of these assets. It is usually estimated as the difference between the revenue generated from selling the asset and the costs of extraction, including costs of materials, labour and a return to the produced capital but excluding taxes, royalties and other costs not directly related to the extraction process, or as net operating surplus plus specific taxes minus a return to capital [20].

The easiest means of estimating the value of the mineral deposit is to base this on the payments due from the extractor to the owner where these two are different entities. Unfortunately such arrangements, typical for XIX century economic environment are rather rare. In addition, whether a valuation based on such payments could be considered as a representation of resource based rent would strongly depend on terms of an underlying agreement. First of all the level of future payments agreed between the owner and extractor should change in response to factors affecting future resource rents like future discoveries, changes in the commodity price of the mineral relative to the overall level of prices and changes in technology. Then such agreement cannot include provisions of a typical benefits-sharing scheme under which an owner retains right to claim, at least partially, results of any or some upward developments in external factors [19].

In absence of classical type rental agreements between owners and extractors the only way remaining is to assume that economic rent is embodied in gross operating surplus of an enterprise. This can be partitioned into two parts, one part relating to the economic rent coming from the use of produced assets, namely fixed capital and the other part resulting from the use of non-produced assets (natural resources). The latter stream represents the resource rent. Such approach leads directly to application of discounted cash flow method albeit with some adjustments.

The pivotal issue regarding resource rent is related to treatment of decrease in value of remaining resources in situ. Here two extreme assumptions can be made. The former one is that the whole of the resource rent can be regarded as income since natural resources are generally abundant enough to cover needs in foreseeable future and thus supposes that any volume left instead of being extracted carries no present value. The opposite proposition states on the contrary that the value of the resource in the future would be the same to future generations as it is to present generations today. There is thus no applicable rate of discount and the whole of the resource rent needs to be treated as the decline in the value of the stock of the natural resource. This view corresponds with an interpretation that revenues obtained from selling natural assets are not income from human activities and therefore should be excluded from relevant Gross Domestic Product, even those coming from the sustainable use of a renewable asset [23].

The vast majority of scholars and experts would reject both above described prepositions and consequently opt for partition of the resource rent between an element which is regarded as income and one which represents the depletion of the asset. The first one to propose a scientific solution to this issue was Harald Hotelling [11]. Subsequently an extensive economic literature on this topic has been accumulated, containing various models defining a split between income from and extraction of natural resources. None of them has got any wide recog- 
nition [19].

Another demanding challenge refers to split between remuneration of man-made assets and natural resources. Net operating surplus, estimated as the difference between the revenue generated from the sale of asset, the costs of labour and materials and consumption of fixed capital, includes the return to all the capital assets of an enterprise, without a direct allocation to fixed assets and natural resources. SEEA in fact recommends to use a "normalised rate of return" applied to fixed assets and to treat a remaining balance as a resource rent. The Statistical Office of the European Communities (Eurostat) task force on subsoil assets suggested using a rate derived from actual data from manufacturing industries or the rate of return to company shareholders. It supposed such a rate would be in the range of 8 to 10 percents [20].

Application of income approach to assessment of mineral assets value faces also a problem of negative results of discounted cash flow analysis. Hence values of subsoil assets are dependent on some particularly volatile parameters like commodity prices, costs, accepted risk levels, in certain circumstances assets primary viewed as quite precious may become valueless. Since mining is one of the most capital intensive industries such situation may not necessarily lead to discontinuation of extraction in existing plants as they might continue operations with long term consideration in mind.

ExxonMobil use to base its key operations on 30 years plan [24]. As oppose to valuation codes which recommend application of real options method, in national accounts quite often such negative resource rents are set equal to zero and corresponding mineral deposits anyway reported in the asset accounts [20].

Dissemination of SEEA still remains limited. It was admitted in 2003 that very few countries had developed a broad range of accounts, and no country has yet developed the full set of accounts [19]. Surprisingly there is a very limited number of presentations regarding implementation of SEEA in particular countries. However one can indicate Norway, Canada, Australia, The Netherlands and several others as clearly committed to this task.

\subsection{Recognizing Mineral Exploration and Closure under National Accounts}

Inclusion of natural resources into National Accounts requires addressing two important issues referred to recognition of:

1) Mineral exploration;

2) Closure of mining activities_-decommissioning of a mine and rehabilitation of land.

Recognition of mineral exploration value at the same time as the one of mineral deposits is a distinctive challenge for national accounts. In the other systems in consideration this problem is non-existent since an assumption of mineral assets evolution through different phases is applied. Therefore a given asset can be either in exploration phase when is valued as exploration rights or in one of later ones when it effectively becomes a cash generating unit (at least potentially). Never appears it simultaneously in both of two phases.

On the contrary, national accounts have to recognise and properly record a very frequent situation, in which exploration rights belong to one entity (usually a mining company or other enterprises running geological works) while a mineral deposit in situ is owned by another (usually a State). Therefore, to be properly included into national statistics both assets have to be properly valued simultaneously.

SEEA accepts two ways of recording costs associated with mineral exploration separately for mineral deposits in situ [19]:

1) As usually the preferred and least feasible option is to record values for both the mineral exploration and the mineral deposit from independent sources;

2) The supplementary option is to register the value of mineral exploration applying either cost or market approach (depending on whether it is carried out by a contractor or on own account) and to calculate the value of the mineral on the differential basis considering the value reached with methods otherwise applied to assess a mineral deposit value as equal to the sum of both components in consideration.

The issue of decommissioning also influences mineral deposits valuation under SEEA. In some cases mining activities involve creation of large extractive structures such as oil rigs or open pits which have to be removed after completion of extraction. At least some land is also to be reclaimed and made available for a new use.

First of all, SEEA underlines that the treatment of decommissioning costs is intrinsic to the valuation of the mineral resource under consideration. It recommends that such costs should be anticipated in a way that over the whole time period the sum of consumption of fixed capital offsets the sum of the original capital formation and the cost of decommissioning [19]. No further guidelines are given as regards methodology to be applied in such 
cases.

\section{Conclusion and Further Developments}

Variety of valuation approaches and methods developed for mineral resources can be considered as a disadvantage, leading to confusions and mistakes. However, giving a variety of assets included into this category as well as diversity of purposes that these developments are going to serve, any standardization attempts have to be undertaken with prudence. Introduction of the SMOG disclosure to financial reporting of oil \& gas companies may serve as a perfect warning example. Discounted cash flow methodology on which SMOG is based and actually represents its simplified and standardized form had been widely recognized and applied well before FASB decided the SMOG introduction. The purpose of this decision sounded clear and well grounded. But the results were very far from expected. Instead of providing additional, valuable information on oil \& gas resources, it increased costs of financial reporting process and created confusion.

It is clear that the majority of mineral assets valuations will be based on income approach thus requiring construction of comprehensive financial models reflecting a wide array of parameters from areas of geology, mining, environmental studies, finance, marketing and politics to name the most important ones. Such models will have to cover a long time spans, making it virtually impossible to set out any rigid methodological rules.

In view of the above professional and regulatory bodies, we shall aim at harmonization of valuation methods and approaches limiting unnecessary redundancies and eliminating different usage of the same notions. Simultaneously they should provision for the existence of qualified professionals capable to properly understand any valuation issue and apply appropriate methods.

\section{References}

[1] Special Committee of the Canadian Institute of Mining, Metallurgy and Petroleum on Valuation of Mineral Properties (2003) Standards and Guidelines for Valuation of Mineral Properties (CIMVAL).

[2] The VALMIN Committee (2005) Code for the Technical Assessment and Valuation of Mineral and Petroleum Assets and Securities for Independent Expert Reports (The VALMIN Code).

[3] United Nations (2010) United Nations Framework Classification for Fossil Energy and Mineral Reserves and Resources 2009. Economic Commission for Europe, ECE Energy Series No. 39, New York, Geneva.

[4] (2012) The Australasian Code for Reporting of Exploration Results, Mineral Resources and Ore Reserves (The JORC 2012 Code).

[5] Nordhaus, W.D. and Kokkelenberg, E.C. (1999) Nature’s Numbers: Expanding the National Economic Accounts to Include the Environment. National Academy Press, Washington D.C.

[6] Cottrell, G. and Cameron, H. (2012) Financial Reporting in the Mining Industry for the 21st Century. Price Waterhouse Coopers. https://openlibrary.org/books/OL18877792M/Financial_reporting_in_the_mining_industry_for_the_21st_century

[7] KPMG (2013) Mining Financial Reporting Trends 2012. KPMG International.

[8] KPMG (2007) Global Mining Reporting Trends 2006. KPMG International.

[9] (2004) International Financial Reporting Standard 6 Exploration for and Evaluation of Mineral Resources, IASCF, London.

[10] European Commission Organisation for Economic Co-operation and Development United Nations World Bank (2013) System of Environmental-Economic Accounting 2012. White Cover Publication, Pre-Edited Text Subject to Official Editing.

[11] Hotelling, H. (1931) The Economics of Exhaustible Resources. Journal of Political Economy, 39, 137-175. http://dx.doi.org/10.1086/254195

[12] Slade, M.E. and Thille, H. (2009) Whither Hotelling: Tests of the Theory of Exhaustible Resources. Annual Review of Resource Economics, 1, 239-260.

[13] Barnett, H.J. and Morse, C. (1963) Scarcity and Growth: The Economics of Natural Resource Availability. Johns Hopkins University Press, Baltimore.

[14] (1994) Accounting for Mineral Resources: Issues and BEA’s Initial Estimates. Survey of Current Business, US Bureau of Economic Analysis Washington DC.

[15] Nordhaus, W.D. (1973) The Allocation of Energy Resources. Brookings Papers on Economic Activity, 1973, 529-570. http://dx.doi.org/10.2307/2534202 
[16] Pindyck, R.S. (1978) The Optimal Exploration and Production of Nonrenewable Resources. Journal of Political Economy, 86, 841-861.

[17] Dasgupta, P. and Heal, G. (1974) The Optimal Depletion of Exhaustible Resources. Paris, The Review of Economic Studies, 41, 3-28. http://dx.doi.org/10.2307/2296369

[18] United Nations (1993) Handbook of National Accounting: Integrated Environmental and Economic Accounting, Interim Version. Studies in Method, Series F, No. 61, New York.

[19] United Nations, European Commission, International Monetary Fund, Organisation for Economic Cooperation and Development and the World Bank (2003) Handbook of National Accounting: Integrated Environmental and Economic Accounting. Studies in Methods, Series F, No. 16, New York.

[20] United Nations (2000) Handbook of National Accounting: Integrated Environmental and Economic Accounting. An Operational Manual. Studies in Methods, Series F, No. 78, New York.

[21] Weatherstone, N. (2008) International Standards for Reporting of Mineral Resources and Reserves—Status, Outlook and Important Issues. World Mining Congress \& Expo, Kraków.

[22] Erlandsen, K., et al. (2004) Subsoil Asset Accounts. Results of a Questionnaire and Points for Further Discussion. 9th Meeting of the London Group on Environmental Accounting Proceedings \& Papers (Draft), Copenhagen, 22-24 September 2004, 101-116.

[23] Vanoli, A. (1995) Reflection on Environmental Accounting Issues. Review of Income and Wealth, 41, 113-137.

[24] Interview with Rex Tillerson, CEO ExxonMobil. Financial Times, 9 March 2009. 
Scientific Research Publishing (SCIRP) is one of the largest Open Access journal publishers. It is currently publishing more than 200 open access, online, peer-reviewed journals covering a wide range of academic disciplines. SCIRP serves the worldwide academic communities and contributes to the progress and application of science with its publication.

Other selected journals from SCIRP are listed as below. Submit your manuscript to us via either submit@scirp.org or Online Submission Portal.
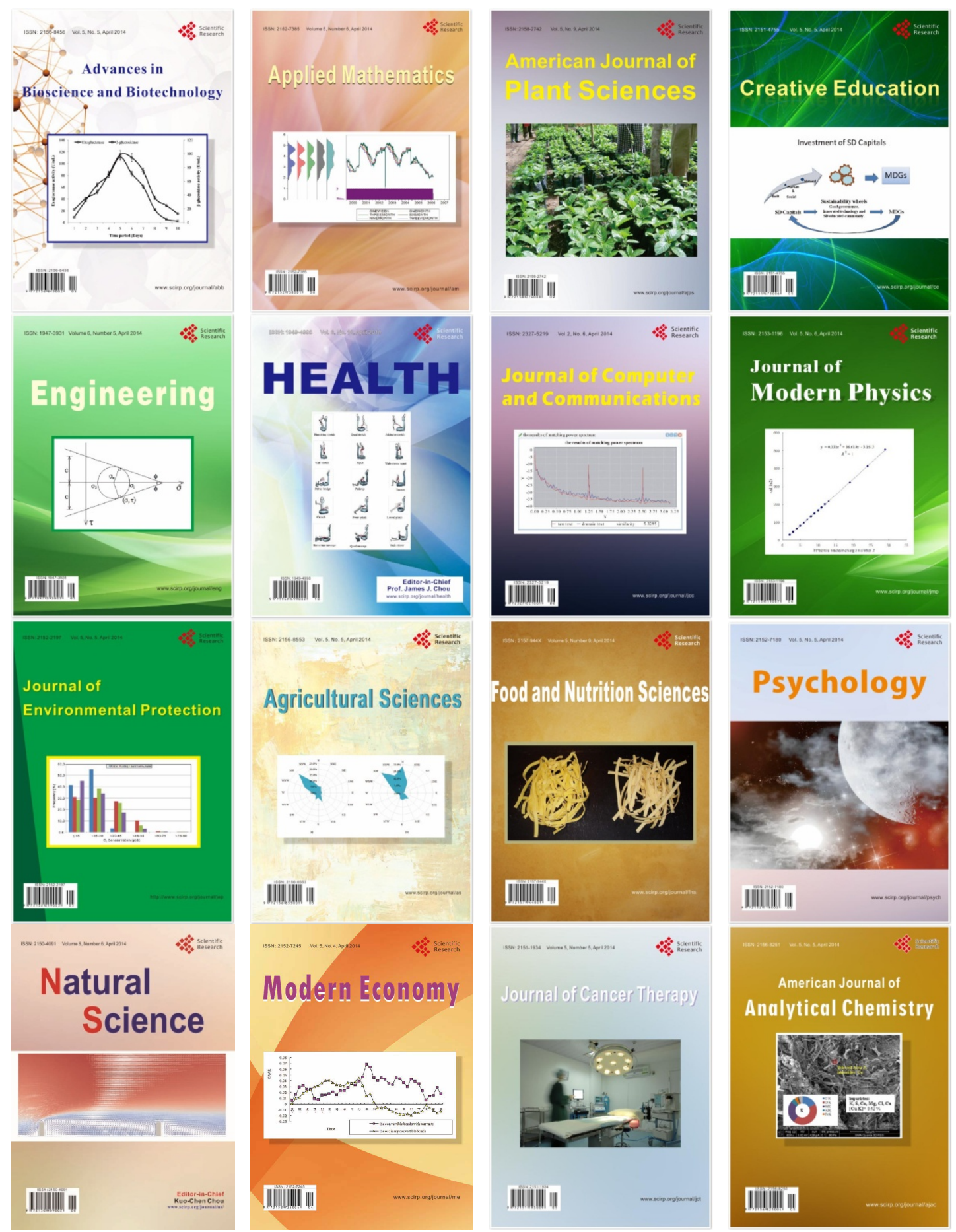